\title{
Dehiscence method: a seed-saving, quick and simple viability assessment in rice
}

\author{
Ling-xiang $\mathrm{Xu}^{1,2}$, Yi-xin Lin ${ }^{1,2}$, Li-hong Wang ${ }^{3}$ and Yuan-chang Zhou ${ }^{1 *}$
}

\begin{abstract}
Background: Seed viability monitoring is very important in ex situ germplasm preservation to detect germplasm deterioration. This requires seed-, time- and labor- saving methods with high precision to assess seed germination as viability. Although the current non-invasive, rapid, sensing methods (NRSs) are time- and labor-saving, they lack the precision and simplicity which are the virtues of traditional germination. Moreover, they consume a considerable amount of seeds to adjust sensed signals to germination percentage, which disregards the seed-saving objective. This becomes particularly severe for rare or endangered species whose seeds are already scarce. Here we propose a new method that is precise, low-invasive, simple, and quick, which involves analyzing the pattern of dehiscence (seed coat rupture), followed by embryonic protrusion.
\end{abstract}

Results: Dehiscence proved simple to identify. After the trial of 20 treatments from 3 rice varieties, we recognized that dehiscence percentage at the 48th hour of germination $(D(48))$ correlates significantly with germination rate for tested seed lots. In addition, we found that the final germination percentage corresponded to D(48) plus 5. More than $70 \%$ of the seeds survived post-dehiscence desiccation for storage. Hydrogen peroxide (1 mM) as the solution for imbibition could further improve the survival. The method also worked quicker than tetrazolium which is honored as a fast, traditional method, in detecting less vigorous but viable seeds.

Conclusion: We demonstrated the comprehensive virtues of dehiscence method in assessing rice seed: it is more precise and easier to use than NRSs and is faster and more seed-saving than traditional methods. We anticipate modifications including artificial intelligence to extend our method to increasingly diverse circumstances and species.

Keywords: Ageing, Dehydration, Deterioration, Dormancy, Drought resistance, Endangered species, Genebank, Orthodox seed, Oryza, Pre-harvest sprout

\section{Background}

Floristic diversity loss which is mainly due to anthropogenic impact is an issue of great concern and is becoming increasingly manifest [1]. Plants are the producers of the globe and it is the floristic diversity that maintains the multifunctionality of the ecosystem [2], sustains its productivity and carbon/nitrogen cycles [3-5], assists the ecosystem resistance to extreme climate [2] and these in turn benefit the diversity of both wild and

\footnotetext{
*Correspondence: zwy_2002@163.com

${ }^{1}$ Key Laboratory of Ministry of Education for Genetics, Breeding and Multiple Utilization of Crops, College of Crop Science, Fujian Agriculture and Forestry University, Jinshan, Fuzhou 350002, People's Republic of China

Full list of author information is available at the end of the article
}

cultivated species [6]. Crop wild relatives and landraces are precious to agriculture, because they bear invaluable genetic resources and are the material basis of agriculture $[7,8]$, like the wild rice (e.g. Oryza rufipogen Griff) which is on the International Conservation Union Red List [8]. Since plant diversity loss threats the world's food security and human welfare, biodiversity conservation is one of the Millennium Development Goals of the United Nations [9]. One plausible and very last solution is the ex situ preservation of seeds by means of "Noah's Ark" or "Alamo" [10]. Cold storage of seeds in genebanks is currently the predominant way to achieve long-term conservation all over the world. The number of germplasm accessions in genebanks achieved 7.4 million in 2010, up to 6.6 million of which are seeds [11]. Seed viability monitoring is indispensable, because the decline of vigor and 
deterioration with time are inevitable, call for seed viability improvement including seed regeneration [12].

Presently predominant methods for monitoring viability in seed banks are germination test, 2,3,5-triphenyltetrazolium hydrochloride dyeing, and electric conductivity measurement [13]. But germination is the overwhelmingly widespread one owing the following advantages (1) precision (successful transition to a seedling means that the seed is viable); (2) simplicity (easy to operate) [14]. Despite its usefulness, this method has drawbacks: post-germination seeds cannot be stored as seeds anymore, and the duration may be too long for early decision on whether an accession should be stored as usual, primed to enhance germination or regenerated [13]. Masses of up-to-date research in this decade focus on the two problems, with the advantage described as either "non-invasive/non-destructive" (N) or "real-time/ rapid" (R), featured with sensing (S) apparatus (NRS method, NRSs) [14-18]. They can be divided into four groups by the property of the signal they sense (Table 1 ). However, none of these methods are widely applied in genebanks. Non-invasive methods are preferred for rare accessions to save seeds, but the methods paradoxically consume seeds to determine germination percentage (GP) for calibration. Another shortcoming is the lack of precision particularly for accessions around the critical node $(\mathrm{GP}=85 \%)$, below which regeneration is probably required [21]. Even supposing advanced [24] or further research manages to precisely link signals and viability, unpredictable factors beyond experimental control such as species [22], variety, seed lot, physiological state [22], technical processes [24, 25, 27], and maternal environment [28] could bewilder testers.

We propose a new method similar to traditional germination in rice. Rice sustains more than half of the world's population and is the staple food in East, Southeast and South Asia, some parts of tropical Africa [29] and Latin America. Its dehiscence, or rupture of the seed coat [30], is a stage just before embryo protrusion, which enables desiccation tolerance (DT) [31]. Unlike previously supposed, seeds do have DT even after radicle or shoot elongation [32-35] and can be dehydrated afterwards for storage. The pattern that shoot protrusion leads to successful germination in rice (Fig. 1, Additional file 1: Figure S1) makes it a possible viability indicator. We sought to establish, to our knowledge, the first report of dehiscence method (DehM) to correlate dehiscence to GP, to satisfy the following criteria: (1) simplicity; (2) precision; (3) post-test viability and storability; (4) quickness over traditional methods.

\section{Methods}

\section{Description of seed materials}

Seeds of various viabilities of three cultivars representing the two main subspecies in China were used in our research: Oryza sativa subsp.geng cv. Nipponbare (NPB), Oryza sativa subsp.xian cv. 93-11 (93-11), and Oryza sativa subsp.geng (bred by Jilin Academy of Agriculture Sciences, JG). NPB was the model species for monocots and their seeds were harvested in 2014 (NPB14) and 2016 (NPB16) with initial GP $>95 \%$. NPB16 were the main material of this experiment for its abundance and its state: harvested over-ripe, and therefore more sensitive to ageing and dehydration. This vulnerability could exhibit whether DehM had detrimental effects. NPB16 experienced the accelerated artificial ageing (AAA) test at $40{ }^{\circ} \mathrm{C}$ and $75 \%$ relative humidity (RH) for various durations: 1 day for NPB16-1d, 2 for NPB16-2d and so on for $-3 \mathrm{~d}, 5 \mathrm{~d}, 5.5 \mathrm{~d}, 8 \mathrm{~d}$. AAA created gradient GP to adjust dehiscence-germination relationship. NPB14 had the advantage of enough time for natural ageing (room temperature, $\sim 25^{\circ} \mathrm{C}$ in winter and $\sim 30^{\circ} \mathrm{C}$ in summer, sealed in aluminum foil bags for $\sim 2.5$ years). The cultivars 93-11 (initial GP > 95\%) and Jigeng were tested simply to examine the correlation between dehiscence percentage (D) and GP. Further treatment information is in Table 2 and Fig. 2. Overripe NPB16 deteriorated significantly more rapidly than non-overripe NPB14.

Table 1 Description of main innovations in NRS methods

\begin{tabular}{|c|c|c|c|}
\hline Biometry method & Origins of sensed signals & Main sensing method & Output of sensing \\
\hline \multirow[t]{2}{*}{ Chemo-metric } & One or a group of chemical components [19] & $\begin{array}{l}\text { Electronic nose [20], } \\
\text { optrode [13], IR } \\
\text { spectroscope }\end{array}$ & Quantity of $\mathrm{O}_{2}[18,21], \mathrm{H}_{2} \mathrm{O}_{2}[21]$, VOCs [20], Protein [22] \\
\hline & Chemical bond: $\mathrm{C}-\mathrm{H}, \mathrm{C}-\mathrm{O}, \mathrm{O}-\mathrm{H}[23]$ & $\begin{array}{l}\text { NIR spectroscope, } \\
\text { hyperspectral imag- } \\
\text { ing }\end{array}$ & $\begin{array}{l}\text { "Heat map" whose quantity in each point can be summed } \\
\text { up }\end{array}$ \\
\hline Calori-metric [14] & Heat & IR spectroscope & \\
\hline Imaging & X-ray $[24,25]$, infrared light, visible light & Photographing & Shape [26], size, color intensity," heat map" \\
\hline
\end{tabular}

VOCs: volatile organic chemicals, $\mathrm{H}_{2} \mathrm{O}_{2}$ : hydrogen peroxide. Imaging method can both work solely or complimentary to other sensing methods. NIR: near-infrared, IR: infrared. Infrared light can be applied in all four groups 

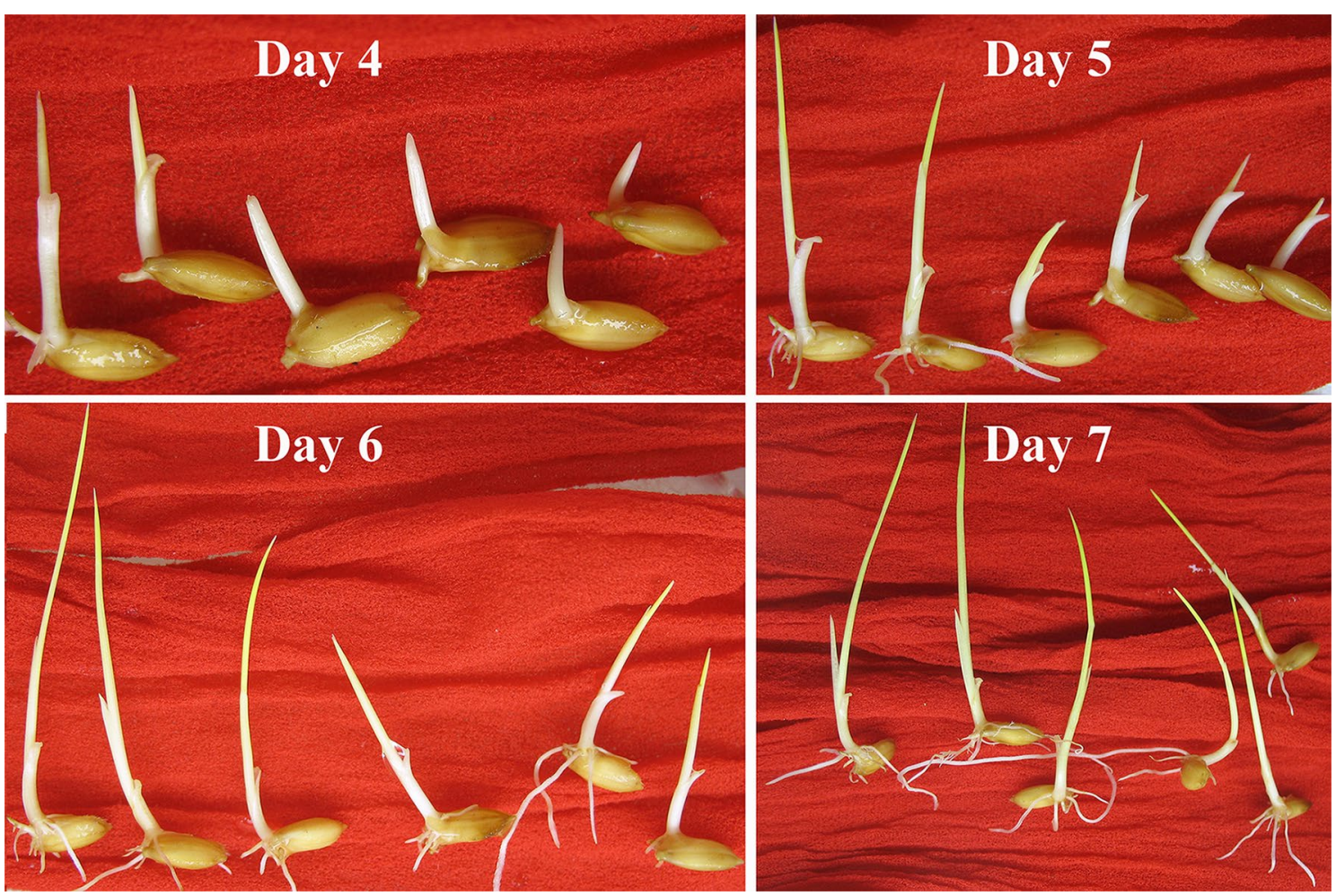

Fig. 1 Germination pattern of 6 low-vigorous but viable seeds without early radicle elongation. These seeds were from the control of NPB16 (GP $\geq 95 \%$ ). Day 4 is probably for early germination counting which can be named germination power in germination analysis, and here the majority of seeds already germinated in $4 \mathrm{~d}$. The 6 seeds which were prospective to germinate for their dehiscence, were picked out for photographing

\section{Table 2 Abbreviation and description of seed treatments}

JG Under uncontrolled ageing treatment (UA, without priming/imbibition) till Jul. 2015 and was then stored at $-18^{\circ} \mathrm{C}$ until Nov. 2017. NPB14-

93-11 UA1 and UA2 were NPB14 seeds of different viability after UA

NPB14

NPB14 NPB14-NA were naturally aged since harvest for 3 years and germination percentage was 28\% NPB14-NA-HP were hydroprimed NPB14-NA

NPB16 N16-1-8d

Post-ageing Priming

Post-Dehiscence Ageing
NPB16 under artificial accelerated ageing (AAA) for 1-8 d NPB16-5d-Spd and NPB16-5d-HP were NPB16-5d primed with $1 \mathrm{mM}$ spermidine and distill water respectively; NPB16-HP were NPB16 primed with distill water without AAA

AAA and natural ageing after recollecting and dehydrating dehiscent seeds previously in distill water or $1 \mathrm{mM}$ hydrogen peroxide

Germination for $24 \mathrm{~h}$ is also the incubation process of priming where seeds were redried before protrusion

\section{Germination and dehiscence tests}

Seed viability was determined by a 7-day germination test according to the criteria provided by ISTA [36] $\left(28{ }^{\circ} \mathrm{C}\right.$ in dark, wet; 50 seeds per box and at least 2 boxes per sample according to seed abundance). Abnormal seedlings in the end of the test were judged as non-viable. Dehiscence assessment was conducted in the same way as germination but dehiscent seeds were recognized according to whether the protrusion of embryo from the hull was detected at 24, 27, 30,33, 36, 37, $48 \mathrm{~h}$ and during 48-60 h of germination. Identified dehiscent seeds were immediately desiccated to their $\sim$ original moisture content at $\sim 11 \% \mathrm{RH}$ for $48 \mathrm{~h}$ by placing them in mesh bags 

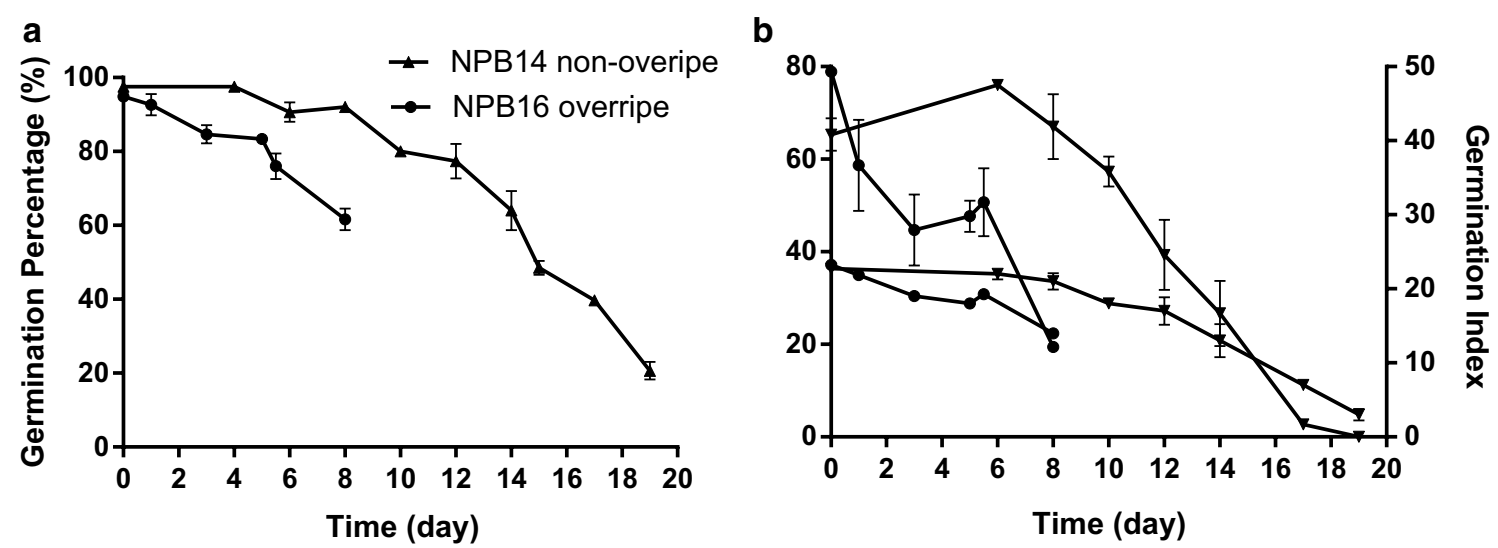

Fig. 2 Deterioration curve for NPB14 (not overripe) and NPB16 (overripe). NPB14 deteriorated significantly slower than NPB16 in all three indexes: germination percentage (a); germination power (4-d germination percentage, $\mathbf{b}$, left axis), and germination index (b, right axis). NPB14 had a period of $8 \mathrm{~d}$ without decline in all three indexes comparing to the initial state but NPB16 deteriorated much more rapidly at the very beginning

over silica gel. Dehiscent seeds were recollected for subsequent post-dehiscence or post-ageing viability tests.

\section{Priming treatment}

Priming was also conducted in the same way as germination but the seeds were recollected for dehydration, usually at $24 \mathrm{~h}$. It was supposed to improve seed viability and was performed on NPB16 and NPB16-5d which had few embryonic protrution by $\sim 24 \mathrm{~h}$. Unlike hydropriming, the solution was instead of distilled water, $1 \mathrm{mM}$ spermidine for NPB16-5d-Spd (analogous to NPB16-5d-HP which used distilled water) and $1 \mathrm{mM} \mathrm{H}_{2} \mathrm{O}_{2}$ [37] (Additional file 2: Table S1) for NPB16-Deh.H1 (analogous to NPB16-Deh.HP). Deh.HP and Deh.H1 mean that the treatments were the same as HP and $\mathrm{H} 1$ respectively, but the duration was until detected seed dehiscence in $24 \mathrm{~h}$, $27 \mathrm{~h}$ and so on to $60 \mathrm{~h}$, as aforesaid, instead of $24 \mathrm{~h}$. As for NPB14-Deh.HP, NPB16-Deh.HP and NPB16-Deh.H1 for comparation, only seeds detected dehiscent at 36-60 h were chosen, in order to avoid bias: those detected at 24-36 $\mathrm{h}$ were too few to be representative.

\section{Viability staining tests}

Seed embryos were longitudinally dissected by a blade and then incubated for $30 \mathrm{~min}$ in $2 \%$ triphenyltetrazolium chloride (TTC/tetrazolium) at $37{ }^{\circ} \mathrm{C}$ for viability evaluation [38].

\section{Data analysis}

Analysis of variance (ANOVA) and regression were performed with SPSS (SPSS Inc, Chicago) or Graphpad Prism (Graphpad Software Ins, La Jolla).

\section{Results}

\section{Simplicity to grasp DehM}

The stage of dehiscence was easy to observe by recognizing notable seed coat split and embryo exposure, probably plumule protrusion to $\leq 0.5 \mathrm{~mm}$ (Fig. $3 \mathrm{~b}, \mathrm{c}$ ). In a 3 h-interval observation, hardly any shoot could elongate to $0.5 \mathrm{~mm}$ without manual detection and even any dehiscent seed was manually neglected, it could not miss next detection $3 \mathrm{~h}$ later. Few NPB seeds at $24 \mathrm{~h}$ of germination protruded except for pre-harvest germination (PHG) seeds, which protruded much faster than the majority and were usually scorched in shoot (Fig. 3a). PHG potentially affects seed DT, and PHG seeds were no longer processed for subsequent desiccation or ageing once recognized. Protrusion of a decayed embryo was also simple to detect (always swollen and translucent; Fig. 3d) and would not be considered as dehiscence.

\section{Precision of DehM in evaluating rice seed germination}

The dehiscence percentage at $48 \mathrm{~h}$ of germination, $\mathrm{D}(48)$, was precisely indicative of germination among the 13 treatments $(G P=60-97 \%)$ and even better for the 10 non-primed ones $(\mathrm{R} \approx 0.95)$ (Table 3 , Fig. 4 ; $\mathrm{D}$ and GP of these 13 treatments were shared by both the left column of Table 3 and Fig. 4b). The correlation was extremely significant for both analyses $(\mathrm{P}<0.0001)$. Non-primed samples with $\mathrm{D}>85 \%$ had GP $>90 \%$, could be considered safe for prolonged storage. To make the projection simple, the equation $\mathrm{GP}=\mathrm{D}+5$ (\%) almost equals the exact germination for non-primed samples with $\mathrm{GP}>85 \% \quad(\mathrm{GP}=1.015 \mathrm{D}+4.559 \quad$ (\%), the equation in Fig. 4a; Table 3). The precision of this equation ceased in samples with post-priming ageing and in those 

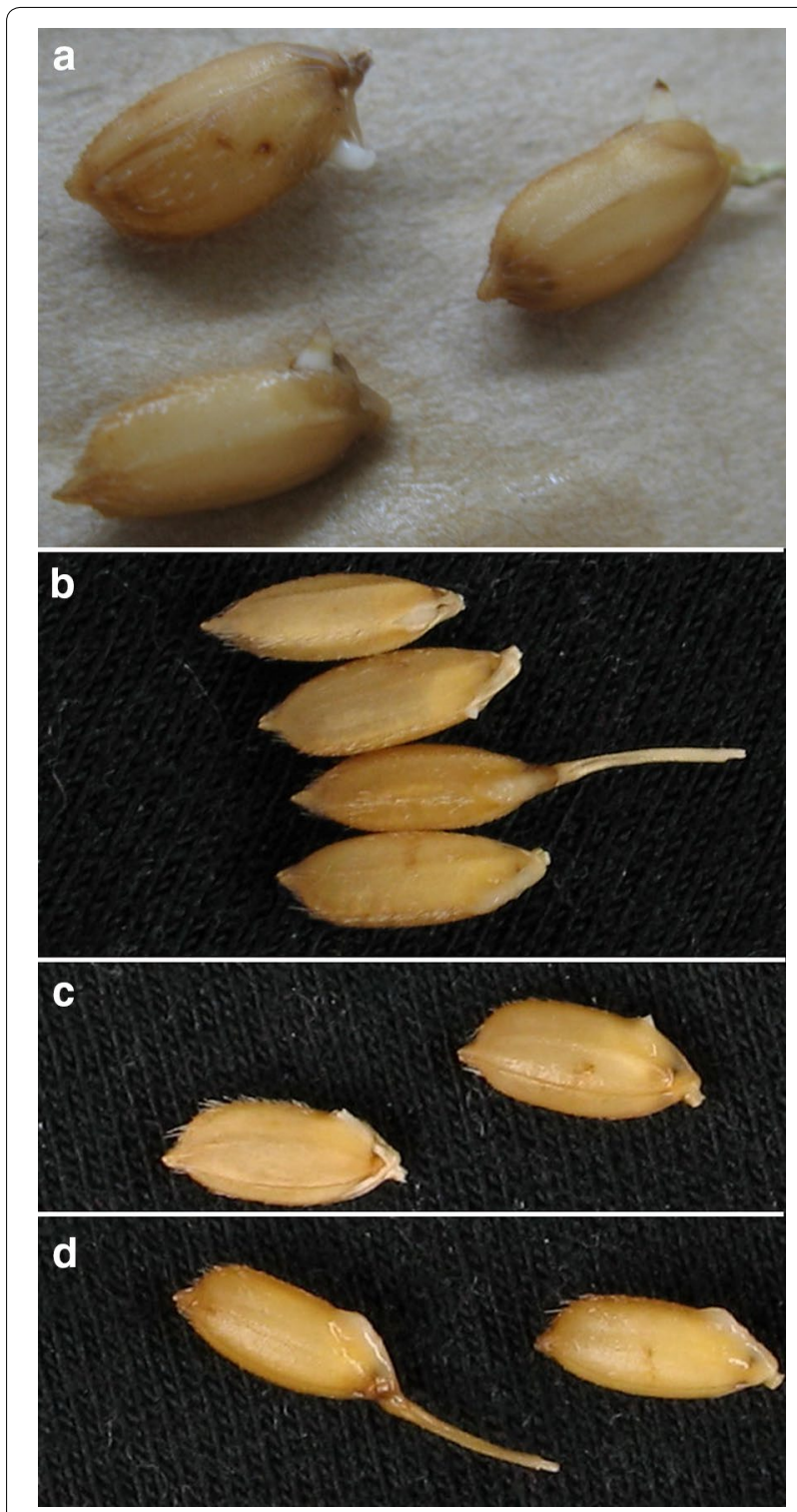

Fig. 3 Seed morphology of dehiscence at $24 \mathrm{~h}$. a Pre-harvest germination of overripe seeds with undue plumule elongation; b, c: normal dehiscence with narrowly recognizable plumule and embryo; d: abnormal dehiscence with rotten embryos, swelling and translucent

with very low germination $(\mathrm{GP}<50 \%)$ which apparently required regeneration. This mismatch became especially apparent in a completely non-viable treatment $(\mathrm{GP}=0$, $\mathrm{D}(48)>50 \%$ ) where ageing declined GP but failed to decrease D synchronously.

\section{Post-test viability of germplasm samples}

The survival rate in recollected NPB16 seeds which experienced $24 \mathrm{~h}$ germination (NPB16-HP, $94.50 \pm 0.69 \%$ ) was higher than those experienced $24-48 \mathrm{~h}$ germination
$(88.32 \pm 1.44 \%$, or $80.27 \pm 4.18 \%$ for those collected after $37 \mathrm{~h}$ ), indicating that the rice gradually lost desiccation tolerance (DT) as protrusion went on. This trend was mitigated by $1 \mathrm{mM}$ hydrogen peroxide $\left(\mathrm{H}_{2} \mathrm{O}_{2}\right)$ (Table 3 ), probably due to resistance inducing.

Post-test seeds maintained their viability for at least 5 months at room temperature with the final GP $\approx 80 \%$ (Table 3). But post-DehM seeds became less likely to germinate in an over-ripe sample (comparing NPB16 to NPB14; Table 3). DehM with $1 \mathrm{mM} \mathrm{H}_{2} \mathrm{O}_{2}$ instead of distilled water alleviated this trend, though not significantly. The survival rate for normal, non-overripe seeds (NPB14, $\mathrm{G} \approx 85 \%$ ) after DehM was over $70 \%$ (Table 3).

\section{Quickness of DehM over germination/TTC}

DehM determined seed viability at as early as $48 \mathrm{~h}$ of germination (Fig. 4). Although detection of viable seeds by TTC was ahead of that by DehM in control (GP $\geq 95 \%$ was labelled $93.3 \%$ by TTC when none of the viable individuals were dehiscent) (Fig. 5, Additional file 3: Table S2), in NPB14-NA-HP dehiscent seeds were mostly judged non-viable by TTC, which could be seen as missing viable seeds. Dehiscent seeds in NPB14-NA-HP dissected for TTC staining plus the non-dissected germinative seeds almost equaled the number of viable seeds which would have been drawn in a standard germination, so it was sound to consider dissected dehiscent seeds as viable. TTC tended to fail to label less vigorous seeds, as it did in seeds of lower germination and in seeds dehisced later in the same accession (Additional file 3: Table S2). The missing viable seeds might well be labelled viable by TTC had they grown more days, but DehM does not require this extra time and so is quicker than TTC.

\section{Discussion}

The intriguing pattern that shoot extrusion meant final germination enabled precise assessment of seed germination by dehiscence observation. DT of dehiscent seed ensured the survival of seeds experiencing postdehiscence desiccation. And the use of $1 \mathrm{mM} \mathrm{H}_{2} \mathrm{O}_{2}$ for imbibition improved not only post-desiccation but also post-AAA survival. Because of these virtues we exhibited, along with the simplicity and short duration of such an experiment, we recommend DehM as a regular way to test viability in rice germplasm.

The main constraint for NRSs application is still the precision, because few of them are able to predict the exact GP around the "critical node", e.g. distinguish between $\mathrm{GP}=78 \%$ and $\mathrm{GP}=88 \%$, the former of which means subsequent population regeneration to improve seed viability and the latter no regeneration. Essentially it is a question of scaling single seed viability up to that of a population as an accession. Although advanced NRSs 
Table 3 Germination and dehiscence percentage of different treatments

\begin{tabular}{|c|c|c|c|c|c|c|}
\hline \multicolumn{4}{|c|}{ Treatments for correlation analysis } & \multicolumn{3}{|c|}{ Treatments excluded for correlation analysis } \\
\hline & $\mathrm{D} \pm \mathrm{SE}(\%)$ & $\mathrm{GP} \pm \mathrm{SE}(\%)$ & $D+5-G P$ & & $\mathrm{D} \pm \mathrm{SE}(\%)$ & $\mathrm{GP} \pm \mathrm{SE}(\%)$ \\
\hline NPB14-UA-1 & $86.00 \pm 6.00$ & $91.00 \pm 1.00$ & 0 & NPB14-NA & $6.00 \pm 1.58$ & $28.29 \pm 2.78$ \\
\hline NPB14-UA-2 & $70.36 \pm 4.34$ & $77.86 \pm 2.69$ & -2.50 & NPB14-NA-HP & $20.26 \pm 5.3$ & $43 \pm 0.71$ \\
\hline NPB16 & $90.00 \pm 0.00$ & $96.00 \pm 0.00$ & -1.00 & NPB14-Spd-6d-HP & $71.00 \pm 3.54$ & 0 \\
\hline NPB16-1d & $89.20 \pm 3.26$ & $94.40 \pm 2.14$ & -0.20 & NPB16-Deh.HP-3d & $96.67 \pm 1.76$ & $28.42 \pm 2.19$ \\
\hline NPB16-2d & $85.00 \pm 1.00$ & $91.00 \pm 1.00$ & -1.00 & NPB16-Deh.H1-3d & $97.00 \pm 2.12$ & $36.15 \pm 3.04^{*}$ \\
\hline NPB16-3d & $79.00 \pm 1.98$ & $84.67 \pm 2.46$ & -0.67 & NPB16-Deh.H1-NA & $99.00 \pm 0.71$ & $78.00 \pm 1.41$ \\
\hline NPB16-5d & $68.00 \pm 0.38$ & $83.30 \pm 0.13$ & -10.30 & NPB16-Deh.HP-NA & $99.00 \pm 0.71$ & $79.00 \pm 0.71$ \\
\hline NPB16-8d & $56.25 \pm 0.00$ & $60.42 \pm 6.25$ & 0.73 & & & \\
\hline $93-11$ & $76.80 \pm 3.01$ & $78.80 \pm 2.94$ & 3.00 & \multicolumn{3}{|c|}{ Pre- and post-dehiscence GP (\%) } \\
\hline$J G$ & $61.00 \pm 13.00$ & $61.00 \pm 19.0$ & 5.00 & & Pre-deh.GP & Post-deh.GP \\
\hline NPB16-HP & $91.50 \pm 0.96$ & $88.50 \pm 0.96$ & 8.00 & NPB14-Deh.HP & 85.71 & $76.39 \pm 0.69^{* *}$ \\
\hline NPB16-5d-Spd & $71.33 \pm 9.68$ & $75.33 \pm 1.33$ & 1.00 & NPB16-Deh.HP & 91.43 & $50 \pm 7.57$ \\
\hline NPB16-5d-HP & $68.67 \pm 8.35$ & $73.33 \pm 1.33$ & 0.34 & NPB16-Deh.H1 & & $62.5 \pm 2.41$ \\
\hline
\end{tabular}

Abbreviation of treatments: NA: natural ageing at room temperature $\left(\sim 25^{\circ} \mathrm{C}\right)$. $\mathrm{HP}, \mathrm{Spd}, \mathrm{H} 1$ : different solutions, distill water, $1 \mathrm{mM}$ spermidine, $1 \mathrm{mM}$ hydrogen peroxide for germination/priming. 1d, 2d, etc.: duration of artificial ageing. Deh.: seeds were desiccated after recognizable dehiscence instead of the 24 th hour of germination. E.g.: NPB14-Spd-6d-HP, Nipponbare harvested in 2014 experiencing 1 mM-Spd priming, 6d-artificial-ageing, hydropriming subsequently. D: dehiscence percentage at the 48th hour of germination. GP: germination percentage; SE: standard error; *GP of NPB16-Deh.H1-3d was significantly higher than NPB16-Deh.HP-3d $(\mathrm{P}<0.05) ;{ }^{* *} \mathrm{GP}$ of NPB14-Deh.HP was extremely significantly higher than NPB16-Deh.HP $(\mathrm{P}<0.01)$. Pre-dehiscence germination of NPB14-Deh.HP, NPB16-Deh.HP and NPB16-Deh.H1 were based on counting leftover non-germinative seeds after DehM

\section{Correlation without post-ageing primed seeds}

a

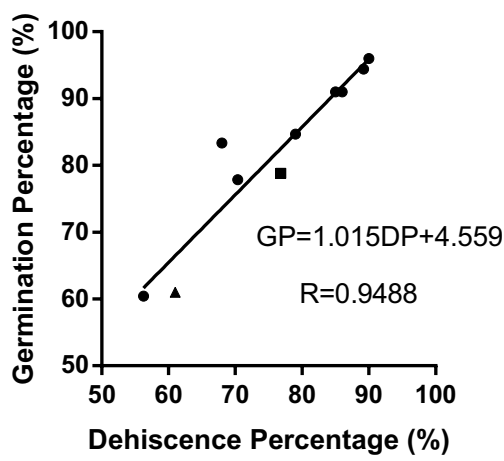

\section{Correlation without post-ageing primed seeds}

b

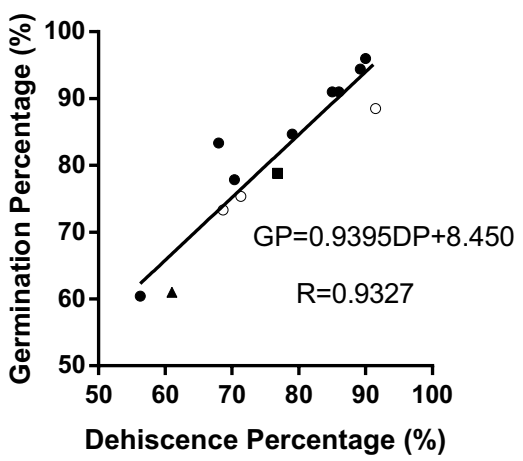

Fig. 4 Correlation of dehiscence percentage at $48 \mathrm{~h}$ to germination percentage. Circle: NPB, square: 93-11, triangle: JG; solid symbols were shared in both $\mathbf{a}$ and $\mathbf{b}$; empty circle: Post-ageing primed NPB samples, excluded from $\mathbf{a}$

can successfully detect loss of viability in a single seed, it is more likely to be used on completely non-viable seed lots, damaged seed lots or those of very low viability, which have significant differences to intact, highly viable seeds. The distribution of single-seed viability in a slightly aged set is likely much more continuous instead of simply "viable/non-viable" [23, 27, 28] or "intact/damage" [30], which makes the seed-viability interpretation more elusive. Based on the accumulation of single seed tested in a "viable/non-viable" way, the exact, more continuous GP is somehow too complicated to predict.

Genetic, physiological, experimental or environmental differences makes the evaluation more difficult, however well the methods work, and no matter what the apparatus senses. Traditional germination fixes these two questions about precision and simplicity, and dehiscence, which is like "semi-germination", seems equally useful for rice but saves more than half of the tested rice seeds which would have been consumed in a germination test. 


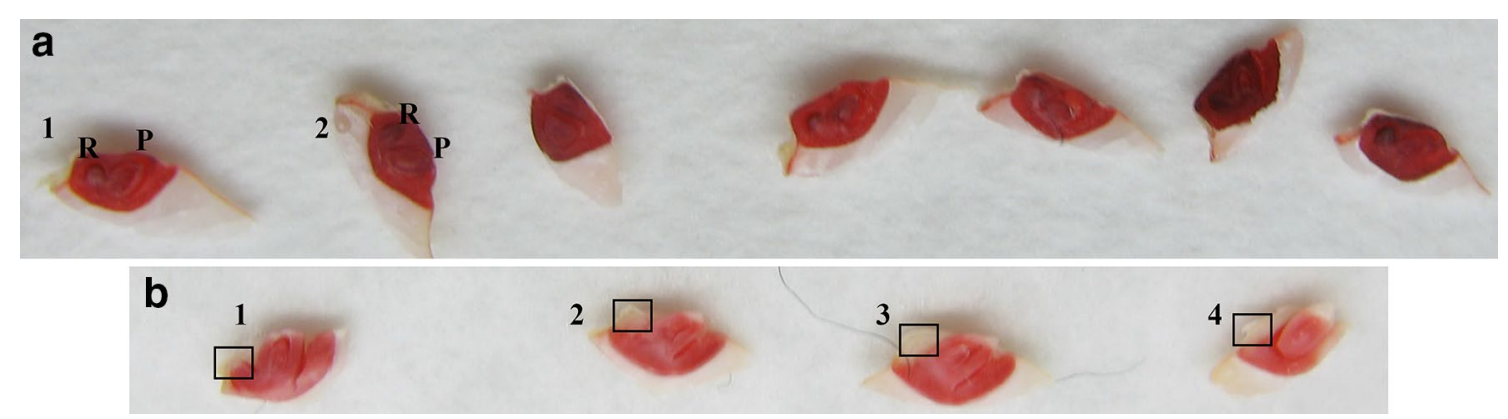

Fig. 5 TTC Staining of control and low-vigorous NPB14 seeds. a In the control (GP $\geq 95 \%)$ seeds were judged viable for they are completely stained, while none of them were dehiscent. Embryo a1 and a2: R, radicle; P, plumule/shoot. All radicles and shoots were entirely stained and none of the shoot protruded out of the top of the embryo. $\mathbf{b}$ In GP $=43 \%$ treatment seeds were judged viable for protrusion of shoots but most of them could not be labelled viable by TTC for failure to stain the radicle area (blank area with the frames). Embryo b1's major radicle was stained but the tip area not. b1's and b3's shoot got broken during the dissecting but were still apparent to protrude as b2 and b4

Table 4 Comparison between 5 methods by 6 criteria

\begin{tabular}{llllll}
\hline & Ger. & TTC & EC & DehM & NRSs \\
\hline Precision & ++ & ++ & - & + & - \\
Seed saving & - & - & + & + & ++ \\
Simplicity & ++ & + & - & + & - \\
Quickness & - & + & + & + & ++ \\
Labor saving & ++ & - & + & + & ++ \\
Single seed screening & - & - & - & + & + \\
\hline
\end{tabular}

++ : perfectly fit; +: well fit; -: not well fit. Ger.: germination method; TTC: tetrazolium method; EC: electrical conductivity method; DehM: dehiscence method; NRSs: non-invasive, rapid sensing method. Labor-saving is the only criterion by which Deh. neither outperformed Ger., nor NRSs. NRSs here only contain chemometry and calorimetry, not morphological graphing

\section{Priority of criteria for monitoring seed viability}

Of all the criteria of viability evaluation, the first-rate importance must be given to precision because precise tests lead to decent warning of the risk that the germplasm faces. Germination method dominates practical viability tests for its irreplaceable precision, which is still the bottleneck for much more advanced methods, especially for accession whose viability is near $80-85 \%$ below which the seeds deteriorate rapidly. The sensitivity of dehiscence to ageing is higher than germination since $1 \%$ decrease in GP usually results in much greater decline in $\mathrm{D}(48)$. Further, seed-saving is of pressing priority for endangered, rare or other precious seeds such as specially treated experimental materials or mutants, and is also beneficial to agricultural production. Last but not least, individual seed viability detection assists screening suitable seeds for storage and propagation. To meet these three primary demands, DehM which can be regarded as semi-germination method and few NRSs are, to our knowledge, the probably applicable ones (Table 4). Quickness is more likely a criterion for production (e.g. sowing in time) or commercial monitoring (e.g. recognizing seed disease and quality) than for conservation, because 7 days is relatively a short period in a well-controlled storage period, probably several or tens of years.

\section{Program for practical application of DehM and possible variations}

To maximize the pros and minimize the cons, an appropriate program for operating DehM is demanded, with the variation of DehM for possible scenarios of the same variety and other varieties or species. We attempted to avoid the risk of overestimating viability which could lead to neglect of germplasm deterioration (Table 5). Underestimating viability be DehM (Table 3, NPB16-5d) is acceptable because more seeds protrude with prolonged germination test and the exact viability can be calculated.

Stage 1 is to exterminate abnormal dehiscence (AD) which means abated storability or inviability. PHG which is usually caused by over-ripening can be recognized by inappropriately early protrusion and scorched plumule. Such seeds are still able to survive and develop but are not recommended for storage. Seed coat rupture with rotten embryo was not likely to happen except for postpriming-ageing seeds where ageing solely diminished viability without apparent effect on the exposure of embryos. Too many decayed embryos is a signal of severe damage corresponding to low viability (much less than $80 \%)$, which makes it not necessary to exert DehM but judged as damaged seeds. However, priming is not likely to be used in seed preservation for it affects the storability [29]. Usually a sample contains 100-200 seeds and at least the first 10 dehiscent ones should be kept to germinate instead of recollected, in order to check the fitness and necessity of DehM on the tested accession.

Another usable variation: to sacrifice labor for post-dehiscence survival, is for very rare or precious 
Table 5 Proposed program for practical use of dehiscence method

\begin{tabular}{|c|c|c|c|}
\hline $\begin{array}{l}\text { Stage } 1 \mathrm{D}=5-10 \% \\
\text { Early } \mathrm{D} \text { quality checking }\end{array}$ & $\begin{array}{l}\text { Stage } 2 \text { 48-h germination } \\
\text { Early viability judging }\end{array}$ & & $\begin{array}{l}\text { Stage } 3 \text { 7-d germination } \\
\text { Final germination judging }\end{array}$ \\
\hline$A D \geq 50 \%$, go to stage 3 & - & & \multirow{3}{*}{$\begin{array}{l}\text { Standard germination tests } \\
\text { to calculate final germina- } \\
\text { tion percentage }\end{array}$} \\
\hline \multirow[t]{2}{*}{$A D<50 \%$} & $D(48) \geq 85 \%$ & Safe storage & \\
\hline & $D(48)<85 \%$ & Judge in Stage 3 & \\
\hline $\begin{array}{l}\text { Excluding rotten and PHG seeds from D counts and } \\
\text { dehydration respectively }\end{array}$ & Dehydrating D(60) & & $\begin{array}{l}\text { Dehydrating } \mathrm{D}(>60) \text { accord- } \\
\text { ing to the preciousness of } \\
\text { the accession }\end{array}$ \\
\hline
\end{tabular}

The dehiscence percentage $D$, which is also a set of the dehiscent seeds, labelled with the duration of germination in hour. $D(60)$ was the dehiscence percentage at $60 \mathrm{~h}$ and was the set of seeds dehiscent before $60 \mathrm{~h}$ among the whole sample. AD: abnormal dehiscence. In our program, the seed viability is more likely to be underestimate, since GP in high viability accessions is usually $5 \%$ higher than $D(48)$. However, as more embryos protrude, an accession which meets the promised germination percentage ( $>85 \%$ ) can be foresaw. For lower viability accessions whose $\mathrm{D}(48)$ is too low to predict germination, this program is essentially a question of sacrificing time for precision and is still perspective both for precision and seed-saving

accessions: reducing the time interval means that seeds are more likely to be picked out for desiccation before their DT gets hampered by protrusion. In our experiments the survival rate reached $100 \%$ for 21 seeds protruded during 36-37 h, at the cost of triple labor of that of $3 \mathrm{~h}$ interval.

The solution for dehiscence test can be chosen for inducing cross-stress resistance [31, 39-41] especially drought-tolerance, such as $\mathrm{H}_{2} \mathrm{O}_{2}$, polyethylene glycol (PEG) [32], abscisic acid (ABA) [33, 40] according to experimental experience. We found the optimal concentration of $\mathrm{H}_{2} \mathrm{O}_{2}$ was $1 \mathrm{mM}$ (Additional file 2: Table S1) and did Peng [37]. However, whether a beneficial resistance-inducing treatment works equally well other circumstances is hard to predict. Resistance-inducing solutions must be used with care and is more probable when it experimentally proved to surpass distilled water. Both PEG and ABA can slow germination, so the time schedule should also be experimentally adjusted.

Our method is also applicable for agricultural production with a germination-promoting machine, which contains seeds in mesh bags and sprays water for imbibition. This usually leads to shoot elongation in rice (Additional file 4: Figure S2). With the implication of DehM, the seeds can be primed inducing stress-resistance and dead seeds can be recognized and abandoned. With advanced experience, this machine can also prime large amount of seeds to the dehiscence period, which saves time and labor in contrast to laboratory germination.

\section{The necessity for DehM to join hands with "intelligence"}

The drawback of our method, labor-intensity is the advantage of NRSs which bear "intelligence" of sensing. One hopeful combination is to bind automatic morphological imaging [34, 42-45], intelligent identifying [46] and robots to replace human labor. Morphological graphing is now feasible in identifying embryo protrusion and has potential to perfect DehM: it records all details during germination and enables accurate operation [47]. Once labor is no longer a problem, the effects of precision and seed-saving can be maximized.

Another possible combination is to use DehM instead of traditional germination method as an expediency, to testify the precision of NRSs and assist their calibration. Traditional TTC staining also complement DehM because TTC staining detects viable, non-dehiscent (dormant) seeds [48].

\section{Expanding the usage to more species}

Crop species are by far not the most endangered plants and the urgency for wild species is punctuated by the species number of floristic germplasm in Chinese national wild-species genebank in Kunming (9484 seed species in 71,232 seed accessions, compared with 712 species in $\sim 400,000$ accessions in Chinese national cropspecies genebank in Beijing [49]). Successful application of DehM to wild species is seemingly a long process, but worth further research. In the shorter run, the dehiscence method is probably more useful for cereal species, and monocot forages whose seeds have hulls such as wild rice, barley (Hordeum vulgare L.), sorghum (Sorghum bicolor (L.) Moench), foxtail millet (Setaria italica L. Beauv.) and lyme grass (Elymus dahuricus Turcz.). The hulls probably assist DT [50] and the protrusion may be similar to rice.

Since forages are less domesticated, dormancy and failure to meet germination requirements complicate viability evaluation (hard to reach $>95 \%$ germination [51]) and still depends on traditional germination or TTC staining, not NRSs. To be more accurate, studies on NRSs are almost exclusively in crop species with uniform germination. Using protrusion to assess germination in non-crop species is needed as an alternative.

Abnormal germination is the main snag for extending DehM. Stored wheat seeds (Triticum aestivum L.) have no hulls and are more prone to decay ( $20 \%$ abnormal 
germination in certain accessions, data not shown here) after protrusion than rice. For this reason, dehiscence does not necessarily mean successful germination. Dicot species, like soybean (Glycine $\max$ (Linn.) Merr.) or rapeseed (Brassica napus L.) are faced with the time lag between radicle protrusion and plumule protrusion. The protrusion and elongation of both ensures successful germination but at this stage, the seed is more likely a seedling and cannot be desiccated. Based simply on radicle protrusion, the rate of abnormal germination is considerable in soybean $(\sim 20 \%$ in a soybean accession, data not shown here). However, there could be a sound relationship between early radicle protrusion and germination. Individuals with rapid protrusion are usually vigorous and prone to germinate. Like rice seeds in this study, late dehiscent individuals cannot germinate and early dehiscent analysis may be extended to other species. Large seeds such as soybean and corn (Zea mays L.) require longer duration to be desiccated and are more desiccation sensitive [50,52], which complicates viability assessing and urges more delicate desiccation.

The potentiality of DehM on orthodox species [53], whether monocot or dicot, needs exploration in respect to the time window [33, 54] for post-protrusion DT and the window for correlation between early protrusion and germination. Earlier, with too short a protrusion, dehiscence cannot be detected, or does not correlate well with germination; later, with too long a protrusion, DT vanishes.

\section{Conclusion}

The demonstrated correlation between early shoot protrusion and successful germination means the count of rice seed dehiscence is a precise indication of germination. Based on this we established DehM which is similar to the traditional germination method of viability assessment and exhibits the same advantages of precision and simplicity. However, it saved $\sim 70 \%$ viable seeds and 4-5 days for decision on the processing of an accession. Proper solution for imbibition which induces stress resistance reinforced the post-testing storability of recollected seeds. Comparing the pros and cons, our method and the highly focused, brand-new NRSs are complimentary to each other. The possibilities of extending it to many other species, with modifications, are infinite.

\section{Additional files}

Additional file 1: Figure S1. Germination pattern of NPB16 (GP $=95 \%)$ of 1, 2, 3, 4 and $7 \mathrm{~d}$. a-e: germination pattern of 56 seeds of 1, 2, 3, 4 and 7 d. f: Line 1,2 , mode level of seed germination of $2 d$, apparent protrusion and initial elongation of shoot; Line 3, narrowly recognizable dehiscent seeds with shoot length $\leq 0.5 \mathrm{~mm}$; Line 4 , non-dehiscent seeds. g: 7 seeds nongerminative in day 4,4 seeds in Line 2 were judged able to germinate; h: the 7 seeds from $g$ in day 7 , all 4 seeds in Line 2 germinated.

Additional file 2: Table $\mathrm{S} 1$. Reasons to set $\mathrm{H}_{2} \mathrm{O}_{2}$ concentration between 1 to $50 \mathrm{mM}$. GP: germination percentage. GP.Ab: percentage of abnormal germination plus normal germination. SE: standard error. Since in NPB14 $50 \mathrm{mM}$ failed to outperform hydropriming and $100 \mathrm{mM}$ seemed even worse, the up limit was deduced below $50 \mathrm{mM}$ and since the in NPB16 was $1 \mathrm{mM} \mathrm{H}_{2} \mathrm{O}_{2}$ did outperform hydropriming but $0.33 \mathrm{mM}$ failed, $1 \mathrm{mM}$ seemed an optimal concentration. Deh.: seeds were desiccated until the time of recognizable dehiscence instead of the 24th hour of germination. E.g.: NPB16-Deh.H1/0.33-3d, Nipponbare harvested in 2016 germinated in $1 / 0.33 \mathrm{mM} \mathrm{H}_{2} \mathrm{O}_{2}$ for recollecting dehiscent seeds and then dehydrated, experienced $3 \mathrm{~d}$-artificial-ageing. HP: hydropriming for $24 \mathrm{~h}$ or in distilled water for until the recognition of dehiscence (Deh.HP). a, b, c: different letters means the samples have significant difference $(P<0.05)$.

Additional file 3: Table S2. Comparison between tetrazolium (TTC) and dehiscent method (DehM) with reference to Germination. TTC(Deh.):

TTC test for dehiscent seeds which was performed for 4 replicates each containing $\sim 25$ seeds. The first $4-5$ seeds were labelled early deh. and later 4-5 labelled late deh., before the 60th hour of germination. Ger.: germination method. GP: germination percentage. NPB14-4,10,15d were from a sub-accession of Niponbare harvested in 2014 (NPB14) experiencing after-ripening in room temperature and then artificial ageing for 4, 10, 15 d respectively.

Additional file 4: Figure S2. Rice protrusion promoting machine. (https://item.taobao.com/item.htm?spm=a230r.1.14.81.271 c5f56M4 eN7D\&id=549178602323\&ns=1\&abbucket=10\#detail, 20180606).

\section{Authors' contributions}

LXX carried out the experiments, data analysis, prepared figures and tables. $L X X$ and $Y C Z$ participated in the design of the study, $L X X$ and $Y X L$ prepared and checked the materials. LHW and YXL revised the manuscript. All authors read and approved the final manuscript.

\section{Author details}

${ }^{1}$ Key Laboratory of Ministry of Education for Genetics, Breeding and Multiple Utilization of Crops, College of Crop Science, Fujian Agriculture and Forestry University, Jinshan, Fuzhou 350002, People's Republic of China. ${ }^{2}$ National Genebank, Institute of Crop Science, Chinese Academy of Agricultural Sciences, Beijing 100081, People's Republic of China. ${ }^{3}$ State Key Laboratory of Food Science and Technology, Jiangnan University, Wuxi 214122, People's Republic of China.

\section{Acknowledgements}

We appreciate Dr. Bao-yin Chen, Technician Meng-ni An for providing experimental materials, Dr. Shen-zao Fu for providing experimental details, Master Ming-xing Deng and Master Ling-yan Zhu for sharing data of seed sprout on wheat and soybean respectively. We are deeply thankful to Ph.D. student Lauren Ashman from Australian National University (Australia) and CSIRO (Australia) for providing valuable English editing suggestions for the whole manuscript.

\section{Competing interests}

The authors declare that they have no competing interests.

Availability of data and materials

The datasets supporting the conclusions are included within the article except that of wheat and soybean germination from our colleagues.

\section{Ethics approval and consent to participate}

Not applicable.

\section{Funding}

This work was supported by the National Key R\&D Program of China (2017YFD0100100). 


\section{Publisher's Note}

Springer Nature remains neutral with regard to jurisdictional claims in published maps and institutional affiliations.

Received: 11 June 2018 Accepted: 30 July 2018

Published online: 10 August 2018

\section{References}

1. Hautier Y, Tilman D, Isbell F, Seabloom EW, Borer ET, Reich PB. Anthropogenic environmental changes affect ecosystem stability via biodiversity. Science. 2015;348:336-40.

2. Soliveres S, van der Plas F, Manning P, Prati D, Gossner MM, Renner SC, Alt $F$, Arndt $H$, Baumgartner $V$, Binkenstein J, et al. Biodiversity at multiple trophic levels is needed for ecosystem multifunctionality. Nature. 2016:536:456-9.

3. Hector A, Schmid B, Beierkuhnlein C, Caldeira MC, Diemer M, Dimitrakopoulos PG, Finn JA, Freitas H, Giller PS, Good J, et al. Plant diversity and productivity experiments in European grasslands. Science. 1999;286:1123-7.

4. Poorter L, van der Sande MT, Thompson J, Arets EJMM, Alarcon A, AlvarezSanchez J, Ascarrunz N, Balvanera P, Barajas-Guzman G, Boit A, et al. Diversity enhances carbon storage in tropical forests. Global Ecol Biogeogr. 2015;24:1314-28

5. Engelhardt KAM, Ritchie ME. Effects of macrophyte species richness on wetland ecosystem functioning and services. Nature. 2001;411:687-9.

6. Thuiller W, Lavorel S, Araujo MB, Sykes MT, Prentice IC. Climate change threats to plant diversity in Europe. Proc Natl Acad Sci USA. 2005:102:8245-50.

7. Nevo E. Genetic diversity in wild cereals. Regional and local studies and their bearing on conservation ex situ and in situ. Genet Resour Crop Evol. 1998:45:355-70

8. Gao LZ, Li DY, Wu XQ, Chen W, Huang ZM, Wei XM. Conservation of wild rice populations: a targeted study of common wild rice Oryza rufipogon from China. Am J Plant Sci. 2012;03:854-68.

9. Guefack J. Statistics on biodiversity. IUCN, Abuja; 2008. https://unsta ts.un.org/unsd/environment/envpdf/UNSD_UNEP_ECA\%20Workshop/ Session\%2006-2\%20Biodiversity\%20statistics\%20(IUCN\%20ROCA).pdf. Accessed 4 June 2018.

10. Kuming Institute of Botany, Chinese Academy of Science. The Germplasm Bank of Wild species. http://www.genobank.org. Accessed 4 June 2018.

11. FAO. The second report on the state of the world's plant genetic resources for food and agriculture. Rome: FAO; 2010.

12. Hay FR, Whitehouse KJ. Rethinking the approach to viability monitoring in seed. Conserv Physiol. 2017:5:1-13.

13. Xin X, Wan YL, Wang WJ, Yin GK, McLamore ES, Lu XX. A real-time, noninvasive, micro-optrode technique for detecting seed viability by using oxygen influx. Sci Rep. 2013;3:1-6.

14. Fu YB, Ahmed Z, Diederichsen A. Towards a better monitoring of seed ageing under ex situ seed conservation. Conserv Physiol. 2015;3:1-16.

15. Woo NS, Badger MR, Pogson BJ. A rapid, non-invasive procedure for quantitative assessment of drought survival using chlorophyll fluorescence. Plant Methods. 2008:4:27.

16. Naik HS, Zhang JP, Lofquist A, Assefa T, Sarkar S, Ackerman D, Singh A, Singh AK, Ganapathysubramanian B. A real-time phenotyping framework using machine learning for plant stress severity rating in soybean. Plant Methods. 2017;13:23.

17. Joalland S, Screpanti C, Liebisch F, Varella HV, Gaume A, Walter A. Comparison of visible imaging, thermography and spectrometry methods to evaluate the effect of Heterodera schachtii inoculation on sugar beets. Plant Methods. 2017;13:73.

18. Rahman A, Cho BK. Assessment of seed quality using non-destructive measurement techniques: a review. Seed Sci Res. 2016;26:285-305.

19. Munz E, Rolletschek H, Oeltze-Jafra S, Fuchs J, Guendel A, Neuberger T, Ortleb S, Jakob PM, Borisjuk L. A functional imaging study of germinating oilseed rape seed. New Phytol. 2017;216:1181-90.

20. Zhao J. Application study of electronic nose in seed viability testing and varieties discrimination. Hohhot: Inner Mongolia University; 2015. (In Chinsese with English abstract)
21. Li JG, Wang Y, Pritchard HW, Wang XF. The fluxes of $\mathrm{H}_{2} \mathrm{O}_{2}$ and $\mathrm{O}_{2}$ can be used to evaluate seed germination and vigor of Caragana korshinskii. Planta. 2014:239:1363-73.

22. Wen DX, Hou HC, Meng AJ, Meng J, Xie LY, Zhang CQ. Rapid evaluation of seed vigor by the absolute content of protein in seed within the same crop. Sci Rep. 2018;8:5569

23. Kusumaningrum D, Lee H, Lohumi S, Mo C, Kim MS, Cho BK. Non-destructive technique for determining the viability of soybean (Glycine max) seeds using FT-NIR spectroscopy. J Sci Food Agric. 2018:98:1734-42.

24. Blunk S, Malik AH, de Heer MI, Ekblad T, Bussell J, Sparkes D, Fredlund K, Sturrock CJ, Mooney SJ. Quantification of seed-soil contact of sugar beet (Beta vulgaris) using X-ray computed tomography. Plant Methods. 2017:13:71.

25. Hughes N, Askew K, Scotson CP, Williams K, Sauze C, Corke F, Doonan $\mathrm{JH}$, Nibau C. Non-destructive, high-content analysis of wheat grain traits using X-ray micro computed tomography. Plant Methods. 2017;13:76.

26. Silva VN, Cicero SM, Bennett M. Associations between X-ray visualised internal tomato seed morphology and germination. Seed Sci Technol. 2013:41:225-34.

27. Ambrose A, Lohumi S, Lee WH, Cho BK. Comparative nondestructive measurement of corn seed viability using Fourier transform nearinfrared (FT-NIR) and Raman spectroscopy. Sens Actuators B Chem. 2016;224:500-6.

28. Kandpal LM, Lohumi S, Kim MS, Kang JS, Cho BK. Near-infrared hyperspectral imaging system coupled with multivariate methods to predict viability and vigor in muskmelon seeds. Sens Actuators B Chem. 2016:229:53444.

29. Hussain S, Zheng M, Khan F, Khaliq A, Fahad S, Peng SB, Huang JL, Cui KH, Nie LX. Benefits of rice seed priming are offset permanently by prolonged storage and the storage conditions. Sci Rep. 2015;5:8101.

30. Wakholi C, Kandpal LM, Lee H, Bae H, Park E, Kim MS, Mo C, Lee WH, Cho BK. Rapid assessment of corn seed viability using short wave infrared line-scan hyperspectral imaging and chemometrics. Sens Actuators B Chem. 2018;255:498-507.

31. Ligterink W, Kodde J, Lammers M, Dassen H, van der Geest AHM, de Maagd RA, Hilhorst HWM. Stress-inducible gene expression and its impact on seed and plant performance: a microarray approach. In: Adkins SW, Ashmore S, Navie SC, editors. Seeds, biology, developments and ecology. Wallingford: CABl; 2007. p. 139-48.

32. Maia J, Dekkers BJW, Provart NJ, Ligterink W, Hilhorst HWM. The re-establishment of desiccation tolerance in germinated Arabidopsis thaliana seeds and its associated transcriptome. PLoS ONE. 2011:6:e29123.

33. Maia J, Dekkers BJW, Dolle MJ, Ligterink W, Hilhorst HWM. Abscisic acid (ABA) sensitivity regulates desiccation tolerance in germinated Arabidopsis seeds. New Phytol. 2014;203:81-93.

34. Blazakis KN, Kosma M, Kostelenos G, Baldoni L, Bufacchi M, Kalaitzis P. Description of olive morphological parameters by using open access software. Plant Methods. 2017;13:111

35. da Rocha CRM, Silva VN, Cicero SM. Sunflower seed vigor evaluation by seedling image analyze. Cienc Rural. 2015;45:970-6.

36. ISTA. International rules for seed testing. Zurich: International Seed Testing Association; 2009.

37. Peng L, Lang SR, Wang Y, Pritchard HW, Wang XF. Modulating role of ROS in re-establishing desiccation tolerance in germinating seeds of Caragana korshinskii Kom. J Exp Bot. 2017;68:3585-601.

38. Ellis RH, Hong TD, Roberts EH. Handbook of seed technology for genebanks. Rome: IBPGR; 1985.

39. Lang SR, Liu XX, Ma G, Lan QY, Wang XF. Identification of desiccation tolerance transcripts potentially involved in rape (Brassica napus L.) seeds development and germination. Plant Physiol Biochem. 2014;83:316-26.

40. Costa MCD, Faria JMR, Jose AC, LigterinkW, Hilhorst HWM. Desiccation tolerance and longevity of germinated Sesbania virgata (Cav.) Pers. seeds. J Seed Sci. 2016;38:50-6.

41. Guimaraes CC, Maia J, Faria JMR, Hilhorst HWM, Ligterink W, Pereira WVS, Jose AC. Changes in gene expression and soluble carbohydrate contents during the imbibition and re-induction of desiccation tolerance in Peltophorum dubium seeds. Seed Sci Technol. 2016;44:125-37.

42. Ambrose A, Kandpal LM, Kim MS, Lee WH, Cho BK. High speed measurement of corn seed viability using hyperspectral imaging. Infrared Phys Technol. 2016;75:173-9. 
43. Silva VN, Cicero SM. Seedling imaging analyze to evaluate eggplant seed physiological potential. Hortic Bras. 2014;32:145-51.

44. Gomes FG, Chamma HMCP, Cicero SM. Automated image analysis of seedlings for vigor evaluation of common bean seeds. Acta Sci Agron. 2014;36:195-200.

45. Abud HF, Cicero SM, Gomes FG. Computerized image analysis of seedlings to evaluate broccoli seed vigor. J Seed Sci. 2017:39:303-10.

46. Dias MAN, Mondo VHV, Cicero SM, Goncalves NR, Da Silva CAT. Vigor tests association as an alternative for precise and efficient assessment of maize seed quality. Rev Caatinga. 2015;28:93-9.

47. Joosen RVL, Kodde J, Willems LAJ, Ligterink W, van der Plas LHW, Hilhorst HWM. GERMINATOR: a software package for high-throughput scoring and curve fitting of Arabidopsis seed germination. Plant J. 2010;62:148-59.

48. Al-Turki TA, Baskin CC. Determination of seed viability of eight wild Saudi Arabian species by germination and X-ray tests. Saudi J Biol Sci. 2017;24:822-9.
49. Lu XX. National Genebank. http://www.cgris.net. Accessed 4 June 2018.

50. Li DZ, Pritchard HW. The science and economics of ex situ plant conservation. Trends Plant Sci. 2009;14:614-21.

51. Lai LM, Chen LJ, Jiang LH, Zhou JH, Zheng YR, Shimizu H. Seed germination of seven desert plants and implications for vegetation restoration. AoB Plants. 2016;8.

52. Tweddle JC, Dickie JB, Baskin CC, Baskin JM. Ecological aspects of seed desiccation sensitivity. J Ecol. 2003;91:294-304.

53. Franchi GG, Piotto B, Nepi M, Baskin CC, Baskin JM, Pacini E. Pollen and seed desiccation tolerance in relation to degree of developmental arrest, dispersal, and survival. J Exp Bot. 2011;62:5267-81.

54. Costa MCD, Righetti K, Nijveen H, Yazdanpanah F, Ligterink W, Buitink J, Hilhorst HWM. A gene co-expression network predicts functional genes controlling the re-establishment of desiccation tolerance in germinated Arabidopsis thaliana seeds. Planta. 2015;242:435-49.
Ready to submit your research? Choose BMC and benefit from:

- fast, convenient online submission

- thorough peer review by experienced researchers in your field

- rapid publication on acceptance

- support for research data, including large and complex data types

- gold Open Access which fosters wider collaboration and increased citations

- maximum visibility for your research: over 100M website views per year

At BMC, research is always in progress.

Learn more biomedcentral.com/submissions 